\title{
A Study of the Teacher's Interactive Decision Making in English Classes of Primary Schools
}

\author{
Sha Zhu \\ Huaiyin Institute of Technology, Huai'an, Jiangsu, China
}

\begin{abstract}
With the development of society, the spirit of creativity is becoming more and more important and should be developed from elementary schools. However, for teachers, some traditional teaching modes still prevail and hinder such progress, and one of them is the rigid implementation of the teaching plan without making interactive decisions in the real class; whereas, making such interactive decisions poses a demanding requirement for the teachers. Therefore, the research intends to explore some strategies to make interactive decisions, and further study the present situation concerning the interactive decision making in the English classes of primary schools. This paper consists of four sections. The first section is the introduction and the second is the literature review, the third section elaborates the research design, the next is the data collection and analysis, which presents and analyzes the representative examples to have a better understanding of interactive decisions, deducing some useful strategies in making interactive decisions as well as summarizing the observation focuses for the next class observation; further gradually reveals the present situation in primary schools through the class observations and interviews of four teachers from different level schools; and the last section concludes the findings and puts forward some suggestions on teachers and schools.
\end{abstract}

Index Terms - interactive decision, primary school, English teachers

\section{INTRODUCTION}

To comply with progress of the society, the new round of curriculum reform was implemented in 2001 in China, which aims against some traditional teaching problems. One of the problems is that for a long time, the teachers are accustomed to teaching in a dominant way while the students are used to learning in a passive way; in the course of time, the students are inclined to become introverted and unconfident, let alone being creative. However, the spirit of creativity is one of the most indispensable demands in modern society and should be developed from the elementary education phase (Liu, 2008). Therefore, education for every student in more perspectives should be concerned, not just their final scores but also their interests and motivations, which are crucial to learning effect but are always ignored in the traditional classes.

In the decade from the curriculum reform, a great deal of achievement has been acquired. However, still a long way to go from the teacher-centered instruction to the student-centered instruction because there are many conflicts between them, and one of them is rigid implementation of the teaching plan. In fact, for teachers, making interactive decisions (short for ID) in class is a good way to help teachers to change the traditional teaching mode; therefore, the researcher intends to carry out an investigation into the present situation involved with interactive decision making in the primary schools in Beijing and further advance some suggestions.

\section{LITERATURE REVIEW}

\section{A. Relevant Literature about Interactive Decisions}

\section{Definition of the interactive decisions}

Lessons are dynamic in nature, to some extent unpredictable, and characterized by constant change. Teachers therefore have to continuously make decisions that are appropriate to the specific dynamics of the lesson they are teaching. These kinds of decisions are called interactive decisions. (Richards, 1996)

\section{Type of the interactive decisions}

From the definition, it can be inferred that ID are dynamic in different situations. Therefore, the type of ID is of great significance for the further study. Johnson (1992b) found that ID are related to different aspects of teaching, including student motivation and involvement, students' language skill and ability, students' affective needs, student understanding, subject matter content, curriculum integration, instructional management, etc. From Zhu's research (2008), interactive decisions are mainly made from the unexpected answers or behaviors from students as well as some unexpected incidents. In this paper, the researcher will adopt Zhu's type in that it is clearer for the later case analysis.

\section{B. Previous Findings about the Interactive Decision Making}

\section{Findings from the Western Countries: the Reggio Emilia Approach}

The Reggio Emilia Approach puts the natural development of children at the center and is adopted by many preschool programs around the world. In this approach, unlike North American predetermined thematic projects, the 
topic of the project may derive directly from teacher observations of children's spontaneous play and exploration, selected on the basis of an academic curiosity or social concern on the part of teachers or parents, or serendipitous events that direct the attention of the children and teachers. What's more, Reggio teachers place a high value on their ability to improvise and respond to children's predisposition to enjoy the unexpected. Projects begin with teachers observing and questioning children about the topic of interest. Based on children's responses, teachers introduce materials, questions, and opportunities that provoke children to further explore the topic (Wikipedia, 2009).

We can see that the Reggio Approach gives a great deal of prominence to the unanticipated resources, which undoubtedly poses a fairly demanding requirement for the teachers.

\section{Findings in China: the findings from Ye Lan}

With the publishing of the works of "To make the Classroom More Vibrant", Professor Ye Lan criticizes the present situation of the pursuit of the traditional teaching modes and then proposes a new concept of teaching, that is, building a dynamic teaching process. She points out that the teaching and learning reform is not implemented very well due to one of many reasons, that is, long periods of misconception of teaching process. From her stand, the value of the classroom teaching in elementary education lies in the interactive process between teacher and students (Ye, 1997). Therefore, in the dynamic process of the interaction in class, the interactive decision making for the teachers is becoming more and more important.

\section{RESEARCH DESIGN}

\section{A. The Research Questions}

Considering that the systematic researches on ID on the subject of English in primary schools in China are few, the researcher will study the present situation of ID in primary schools in the following 3 perspectives, that is:

1) What are some strategies in the successful interactive decision making cases in English classes of primary schools?

2) What is the present situation of interactive decision making in different level schools, an ordinary one and a key one? What are the similarities between them in interactive decision making? What are the differences between them in interactive decision making?

3) Are there any differences between the teachers with different teaching years in interactive decision making?

\section{B. The Research Participants}

To have a general investigation into the present situation in interactive decision making in primary schools, the researcher chooses schools in different levels to study, thereby, two primary schools in Haidian District, Beijing, one is an ordinary school and the other is a key school, are selected as the main research fields for the present research. Both of the two schools selected have a comparatively open teaching and learning environment.

Four female English teachers who taught the students in the fourth grade are chosen as the main participants in this paper in that these students have a better command of English than those in the lower grades while they have less exam burden than those in the higher grades. Considering the demanding requirements for the successful interactive decision making, all the four teachers selected are excellent teachers at the two schools and their teaching are relatively flexible in their own schools. From every school, two teachers, one having taught for about 20 years and the other about 10 years, are chosen respectively, that is, teacher A in the ordinary school with the teaching years of 23 , teacher B in the same ordinary school with the teaching years of 12 , teacher $\mathrm{C}$ in the key school with the teaching years of 21 , teacher D in the same ordinary school with the teaching years of 10 .

\section{The Research Instruments}

Two instruments of classroom observation and interview are employed in the study.

\section{Class Observation}

In order to explore the present situation in interactive decision making, the researcher first presents and analyzes some representative successful examples of ID, collected both from the journals in CNKI and from the researcher's own class observations, to elicit some useful strategies and further, the observation focuses for the phase of open class observation.

The open class observation of the 4 teachers starts from the beginning of April to the end of June, 2011, nearly 3 months, and averagely 2 classes of each teacher in ordinary school while averagely 1 class of each teacher in key school every week, the total number of the classes which are observed for teacher A, B, C, and D is 20, 21, 12, and 11 respectively. The researcher also videotapes all the classes for being re-watched to obtain every possible ID.

Before class, the researcher reads the teacher's teaching plans and discuses with the teachers to know their original teaching design. In class, the researcher takes notes of the significant points concerned with every ID; after class, the researcher re-watches the video of the class to ensure ID and analyzes the notes, and when necessary, interviews the teachers timely on some doubtful points of certain ID.

\section{Interview}

In order to reveal the teacher's own reflection over ID, in the later phase of the class observation, approximately in the middle of June, the researcher takes semi-structured face-to-face interviews with the 4 teachers concerned with three 
aspects of interactive decision making, that is, their attitudes towards interactive decision making, their real use of interactive decision making and the possible factors influencing interactive decision making from their stands.

Before the final semi-structured interviews, in the nearly three months, the researcher has gradually been familiar with the four teachers and had some informal conversations with them, therefore, when taking the final formal interviews, all the teachers express their ideas quite freely.

\section{Data COLlECtion AND ANALYSIS}

In this chapter, the research will first present the representative examples of ID with the analysis of every example to summarize some strategies, and then present a table and the analysis of the class observations of the four teachers; and at last, present the summaries of the interviews of the four teachers.

\section{A. Class Observation}

\section{The Representative Examples of the Successful Interactive Decision Making}

1) The topic of the class was season. The teacher designed such a question.

T: What color is summer? (The students all raised their hands to answer the question.)

S1: I think summer is red, because summer is hot. In summer, the sun is red.

$\mathrm{S} 2$ : I think summer is blue, because in summer the sky is blue, the sea is blue, too. I can swim in the sea...

S3: ...

(Fewer and fewer students raised their hands but a girl still raised her hand highly.)

T: Tell us your opinion, Nancy.

$\mathrm{N}$ (Nancy): Summer is colorful.

(All the other students felt very surprised when hearing this unexpected answer. The teacher also was surprised but continued the exploration of the unexpected answer by asking the other students to guess the reason. Then the whole class started heated discussion.)

S1: Maybe she can wear a colorful dress in summer.

S2: Maybe she has a colorful umbrella.

S3: Maybe she can pick up colorful shells at the beach.

S4: Maybe she likes the colorful flowers in summer.

(The students all tried but no one was correct. At last, Nancy gave her answer.)

$\mathrm{N}$ : Because I like beautiful rainbows. I can see a colorful rainbow in summer.

(After hearing Nancy's unexpected but reasonable answer, all the students clapped their hands for her.) (Chen, 2007)

Analysis: The student's special answer triggers the teacher's interactive decision. To answer teacher's question, the students with different characteristics and backgrounds will give quite different answers, which can provide the teacher with a large amount of information. This teacher is a good listener, captures the student's special and meaningful answer and uses it as a new teaching resource to further guide the students to find out the reason; consequently, he stimulates students' logic and practise their language, making the whole classroom energetic. At the same time, the student who gave this special answer also felt very satisfied to get the confirmation from both the teacher and other students.

What's more, we can see the special answer is elicited by the teacher's figurative and open question, which stimulates the students' imagination and provide a wide space for the students to have free expression based on their special and distinctive experience. Therefore, such open questions or activities are quite significant for the generation of the students' different and imaginative answers and should be designed more in the English classes.

2) The topic of the class was number. The teacher designed an activity in which she asked a student to go to the teacher's desk with the back facing the other students and to count the number of the boys or girls by listening to their expression of "I'm a boy" or "I'm a girl" to practise the sentence pattern of "how many". At the beginning, the students were very interested and everything was in order. But after several times, they gradually lost their interest and a boy spread his arms to pretend to fly and said "I'm a bird." All the class burst out a great laughter. Instead of criticizing him, the teacher praised the student: "Oh! What wonderful imagination!" and even added "how many birds..." into the question list. It was unexpected that the students' interest was stimulated again and the newly adapted activity attained better effect in an active environment. (Feng, 2006)

Analysis: The student's unexpected answer triggers the teacher's interactive decision. Children have quite different thinking mode with the adults and sometimes are more imaginative than adults. The child in the example is so naughty that gives such an unexpected answer, which is probably ignored or even criticized by the teachers in the traditional classes, whereas, the teachers in the example did not criticize the student but adjusted the original activity a little by connecting the unexpected answer with the planned content, not only reinforcing the learning effect but also maintaining the student's valuable imagination.

3) T: What do you have, Sam?

S: (Pointing at the cap on his head) I have a cup. (The teacher heard his mistake but didn't point it out directly.)

T: Show me your cup, please.

$\mathrm{S}$ :(raising his cap) ok. This is my cup.

T: Boys and girls, what does Sam have? 
Ss: Sam has a cap.

T: Very good. Does Sam have a cup?

Ss: No.

T: Can he put a cup on his head?

Ss: No.

T: So, this is a cap, not a cup. Sam, what do you have?

S: I have a cap. (Zhang, 2007)

Analysis: The student's unexpected mistake answer triggers the teacher's interactive decision. The teacher didn't point out the mistake directly but guided him and the other students to realize the mistake in a situational way, which on the one hand helps them acquire the language point, on the other hand, maintains the student's self-esteem.

4) In one English class of Teacher A, she was teaching the students three new words of "doctor", "nurse" and "dentist" by presenting them through different behaviors. When presenting "dentist", the teacher acted as a patient whose teeth hurt, when presenting "nurse", the teacher behaved like a nurse to give the patient an injection, just at this time, a naughty boy was "shouting" as if he was really injected, and the whole class burst into a great laughter. The teacher "punished" him by asking the boy to go to the front to do the different actions again and again to help the other students to know the three words better. As a result, the boy acted quite vividly and the whole class acquired the three words in the laughter.

Analysis: In the primary school, TPR are used a lot in the English classes, and the students at this phase are naughty and active by nature, therefore, some unexpected behavior will often happen in the class. In our traditional teaching, such behavior is probably regarded as "discipline violation" and the student will be criticized but in this example, the teacher tactfully used the student's behavior to help the students learn better; at the same time, "punish" the particular student in a special way.

5) A teacher was teaching "the present continuous tense". But just when everything went well, students' attention was caught by noises from the playground - some students were playing on the playground. The teacher felt very annoyed and wanted to criticize them but had another thought in his mind:

T: What a fine day! And there are so many students on the playground. Can you tell me what they are doing?

S1: They are playing basketball.

S2: They are running.

S3: They are playing ballgames.

(The students raised their hands actively, much beyond the teacher's anticipation.) (Wang, 2011)

Analysis: In this example, the change of the learning atmosphere because of the students' interest triggers the teacher's interactive decision. The primary school students are active by nature and have a relatively short attention span, which usually interrupts the teacher's teaching plan. Yet this teacher perceived the students' interest, changed part of the original teaching plan and used the playground as a real context for the students to practise the tense, still meeting the original teaching objective with a better effect.

6) This is a 6th-grade English class with a revision of the "the simple past tense", the teacher first asked the students to say the tense's characteristics and then to make some sentences. Suddenly, an old woman walked straightly towards one student and said something to her. At last she turned around to say sorry to the teacher and went away. Having seen this, the whole class was in chaos and some students were laughing while the others were whispering with one another. At this point, instead of criticizing them, she asked the students to describe what the old woman said and did just now with "the simple past tense".

S1: She came to our classroom and saw her granddaughter just now.

S2: She gave her the medicine for cough.

S3: She said sorry to us a moment ago.

(Some even asked the girl: did your grandmother ...or what did your grandmother tell you? The students answered their questions one by one and the real interaction between the students began and the whole class became extremely active.) (Ding, 2010)

Analysis: The incident seems unrelated to the teaching content, even can be regarded as "accidents", which easily makes the whole class in chaos. Some of the teachers may criticize the students and force them to concentrate their attention, however, if so, the classroom atmosphere may become tense and the students will not practise English in an active way. Tactfully, the teacher in the example subtly transforms the "accidents" to real contexts for the students to practise English, even makes the students start real communication with each other, successfully changing teaching regrets to teaching shining points.

\section{B. Class Observations of the Four Teachers}

After the analysis of ID, some key points for the class observation can be deduced. They are as follows: 1) How many open questions or activities are there in the class? 2) How many ID related with unexpected answers are there in the class? 3) How many ID related with unexpected behavior are there in the class? 4) How many ID related with unexpected incidents are there in the class? 5) What are the teachers' reactions and solutions towards the unexpected 
resources?

Since ID observed from every teacher can not be presented one by one, the researcher will first present a table of the number of ID in different aspects used by every teacher and then give the detailed descriptions of their individual interactive decision making.

The following is the table. $\mathrm{C}$ for the total number of the classes of every teacher; $\mathrm{T}$ for the total number of ID for every teacher, $\mathrm{O}$ for the number of the open questions or activities for every teacher; A for the number of ID related with unexpected answers for every teacher, B for the number of ID related with unexpected behavior for every teacher; I for the number of ID related with unexpected incidents for every teacher.

\begin{tabular}{|l|l|l|l|l|l|l|}
\hline & $\mathrm{C}$ & $\mathrm{T}$ & $\mathrm{O}$ & $\mathrm{A}$ & $\mathrm{B}$ & $\mathrm{I}$ \\
\hline $\mathrm{A}$ & 20 & 30 & 7 & 8 & 8 & 7 \\
\hline $\mathrm{B}$ & 21 & 21 & 5 & 10 & 2 & 4 \\
\hline $\mathrm{C}$ & 12 & 32 & 10 & 8 & 5 & 9 \\
\hline $\mathrm{D}$ & 10 & 32 & 10 & 10 & 4 & 8 \\
\hline
\end{tabular}

\section{Teacher A:}

In the 20 classes observed, generally speaking, the atmosphere of her classes is comparatively democratic and relaxed. She is very good at making ID related with unexpected behavior. Similarly, she has experience to use incidents as the real context. She also has some experience to make ID related with unexpected answer. Whereas, the interesting and open questions or activities are just a few in her class, and she doesn't make good use of the students' unexpected mistakes to help the students to have a better understanding of the language points. What' more, her teaching objectives are mainly in the knowledge part. Besides, the textbook she used is conversation-oriented, which contains fewer contexts than the story-oriented textbook used by the key school teachers.

2. Teacher B:

In her 21 classes observed, generally speaking, the atmosphere of her classes is not very democratic and quite intense for the students and even for the researcher. However, she is supportive for the students' unexpected answers and sometimes makes such ID to promote more language practice. Nevertheless, her teaching is comparatively traditional, more drill on reading, translation, doing writing exercises in the textbooks while fewer open and interesting questions and activities. She is not patient with the students' mistakes, especially the unexpected mistakes. Moreover, she deals with the students' unexpected behavior and unexpected incidents in a traditional way. Her teaching objectives are mainly in the knowledge part.

3. Teacher C:

In her 12 classes observed, the atmosphere of her classes is very democratic and interesting. She has a good relationship with her students. There are some open questions and activities that are close to her students' life, some of which are adapted from the textbook, the others are designed beyond the textbooks. She welcomes the unexpected answers from the students. She uses the indirect way to deal with the unexpected behavior to save certain students' face. She is also good at using the incidents in her class. However, she doesn't do very well in dealing with the unexpected mistakes from the students. The textbook she uses is story-oriented, which contains more contexts than the conversation-oriented textbook used by the teachers from the ordinary school. Her teaching objectives are both in the knowledge part and in the emotional part.

4. Teacher D:

Her classes are democratic and extremely active compared with the other three teachers. The relationship between the teacher and the students are very close. She often spontaneously asks some questions which are very close to her students' life. Some of the questions she designed are also very open and help to stimulate the students' imagination. She tries her best to make ID to help the students to practise their oral English. She knows her students quite well and specially gets to know the students' interests and needs before class. She also encourages student's unique ideas. But she is not good at dealing with the unexpected behavior, that is, she didn't give the naughty boys opportunities to answer any questions in one whole class as the punishment. She is not very good at using some incidents to make interactive decision. Her teaching objectives are both in the knowledge part and in the emotional part.

\section{Interviews of the Four Teachers}

\section{Teacher A:}

She doesn't welcome the unexpected resources because she thinks they interrupt the teaching plan and it is quite difficult for her to keep the children in order and the children learn little from it. After all, the exam burden is still quite heavy for such ordinary school because of the general low level of the students. But when the unexpected resources really happen, if time permits, she will make some necessary changes to both explore the value and meet the teaching objectives. Moreover, from her point of view, the teacher's questions, especially the open questions can elicit students' unexpected answers. The teacher's own language proficiency and teaching experience also matter.

\section{Teacher B:}

The teacher thinks interactive decision making is not significant, especially in the exam-oriented society. If time permits, she sometimes will adapt the teaching to make ID on the condition that she still can meet the original teaching objectives, which is the most important standards of a good class from her point of view. She also thinks her oral 
English is not very good and sometimes it's not easy for her to speak some English in an improvised manner, which is another reason against her flexible interactive decision making. The teacher regards the unexpected behavior and incidents as "violating the discipline" and her solution is criticism of related students. Since she doesn't value interactive decision making, she doesn't say too much about the factors influencing interactive decision making.

3. Teacher C:

The teacher values interactive decision making because the improvised communication between her students and her is quite crucial in her consideration. Moreover, she thinks the logic development of the students also counts a lot, thus, she values the unexpected and meaningful resources from the students and will try her best to find their value and use it in a positive way, even if she has to change the teaching content and objective, because she thinks in English classes, the teaching content should not be fixed and can be changed within a unit or even units. If the students' interest or curiosity is gone, it's lost forever. She thinks the unexpected resources can help her know better about children's thinking, further help her motivate their learning interest and improve their learning efficiency. Most importantly, the teacher highlights the use of language, which is a key to the positive attitudes towards interactive decision making. However, she thinks she still needs to reflect more and deeper about her success and failure in using the unexpected resources after class in order to do better next time.

4. Teacher D:

She thinks that to make ID can always give her a good opportunity to create a real communication context for the students. She knows unexpected resource is a challenge for her but in her nature, she likes challenges very much. Thus, when the unexpected resources happen, she will try her best to find its value and make the necessary changes of the teaching plan to use it. She thinks the flexible interactive decision making needs long time of teaching practice while she is still very young. She will give the chances to different level students and encourages them to say whatever they want to say, so it's quite often for her to have improvised conversation with them. She likes speaking English herself and is also proficient in it. Besides, she thinks the paramount goal of the language teaching in the elementary school is the development of the children's interests in English; consequently, she puts great emphasis on the design of some open questions and activities. Since she thinks the flexible interactive decision making needs long time of accumulation while she is still very young, she wants to receive more related training and have more learning from the experienced teachers through more communication with them or watches more of their live classes.

\section{FIndings AND SugGestions}

In this chapter, the researcher will first reveal the findings from the representative examples, the findings from class observations and interviews of the four teachers and then advance some suggestions both on the teachers and the schools.

\section{A. Findings}

\section{Findings from representative examples of the successful interactive decision making}

a. The teachers should design more open questions or activities which are close to the student's life and can elicit distinctive answers from different students.

b. When facing the unexpected resources, the teachers can make good use of them to guide the students to continue exploring, like the activity of guessing, with the aim of more language practice in a certain context.

c. When facing the unexpected resources, the teachers can adjust the original activities by using some element of the unexpected resources and still can meet the teaching objective, even with better effect.

d. The unexpected mistake resource is a good opportunity for the teacher to use to help the student and even other students. The teachers should guide the students to realize their mistakes in an indirect way in the given situation.

e. The unexpected behavior of some students, the underlying interests and needs of the students and some incidents in class can be tactfully used by teachers to create a real context for the students to practise their oral English, which is always a crucial goal in English classes, especially in the primary schools.

f. Judging from all the examples, it can be concluded that the key to the successful interactive decision making is tactful association of the unexpected resources with the teaching content in that class and the prerequisite is the teacher's open minds towards them.

\section{Findings from the Class Observations of the Four Teachers}

a. The general findings about interactive decision making

1) When the class atmosphere is relaxed and democratic, teachers tend to make ID.

2) When the teacher makes good use of unexpected resources, the whole class, including both the teacher and the students, are very happy and relaxed. The students are more willing to express their feelings and various ideas and not nervous any more.

3) The textbooks the teachers from the key school use are story-oriented, which contain more contexts than the conversation-oriented textbooks the ordinary school teachers use. More contexts may be much more beneficial for the generation of students' answers in that they provide various contexts for the language learning.

b. The similarities in interactive decision making between the key school and the ordinary school

1) All of the four teachers can make different types of ID appropriately sometimes. 
2) Interactive decision making related with unexpected mistakes is rarely appropriately made in all the four teachers' classes.

c. The differences in interactive decision making between the key School and the ordinary School

1) There is more interactive decision making in the classes of the key school than the ordinary school.

2) The teachers in the key school design more open, interesting questions and activities for the students than the teachers in the ordinary school.

3) The teachers in the key school are more improvised to interactive with the students than the teachers in the ordinary school while the teachers in the ordinary school still adopt more drilling than real communication.

4) The teaching objectives in the ordinary school principally focus on the knowledge dimension, while the teaching objectives in the key school focus on both the knowledge dimension and the emotional dimension.

5) The teachers in the key school are concerned much more with the students' interests and needs than those in the ordinary school.

\section{Findings from the Interviews of the Four Teachers}

a. The similarities in interactive decision making between the key School and the ordinary School

1) All the teachers realize the value of interactive decision making.

2) All the teachers account teacher's own language proficiency as an important factor in interactive decision making successfully.

b. The differences in interactive decision making between the key school and the ordinary school

1) The teachers from the ordinary school don't hold a positive attitude towards ID while the teachers from the key school welcome ID.

2) The teachers from the key school will find the value of ID and try to use them in a positive way while the teachers from the ordinary school will use them if time permits, otherwise, they will skip them and just continue the lesson.

3) The teachers from the ordinary school think of the result of the learning as their main consideration while the teachers from the key school regard the development of children the most important.

4) The teachers from the key school regard the interest for English as the ultimate goal for the primary education while the teachers from the ordinary school mention little.

5) The teachers from the key school consider teacher's reflection ability after class as a crucial factor in making interactive decision successfully while the teachers from the ordinary school mention little.

\section{Findings about the relationship between the teaching years and the interactive decision making}

1) The teachers with more teaching years tend to be more experienced in coping with students' unexpected behavior and incidents.

2) Among all the four teachers, teacher A is relatively better than the other three teachers, perhaps because of her 20 years of the management of the naughty students in the ordinary school, and such students are more difficult to manipulate than those in the key school.

\section{B. Suggestions}

\section{Suggestions on the Teachers}

1) Teachers should change their traditional concepts about teaching.

Firstly, they should have a comprehensive understanding of the teaching plan, that is, just a guideline for the teachers since the real teaching is changing all the time.

Secondly, some teachers' teaching objectives are still mainly in the knowledge part, which is not helpful for interactive decision making because they focus more on the knowledge accumulation not on children's full development. In fact, if the students' emotional needs are fully met, their learning will accordingly be greatly improved.

2) Teachers should improve their ability to make interactive decisions tactfully.

Firstly, teachers should create a democratic and relaxed class environment, where the students incline to produce unique even creative ideas and the whole classroom will be more energetic and the teachers should be supportive and encouraging towards these ideas, even some absurd ones because they are the valuable reflection of the students' own thinking. If the teacher ignores them, they will be gone forever. Gradually, the student's curiosity and exploration will also be gone.

Secondly, teachers should design more open and interesting questions and activities, which can activate the students' thinking, especially their imagination.

Thirdly, teachers should pay more attention on the interactive decision making. The teacher should first judge its value to see which resources can still meet the teaching objectives and which can promote the students' other development and then try to integrate it into the teaching plan before class. Sometimes, the teacher even can adjust the teaching objective to the later classes. The teacher can use one student's unexpected answer or his initiative question as a trigger to encourage the other students to think and communicate with each other to help students practise more English. As for the student's unexpected mistakes, the teacher can use them as teaching resources to help the students learn English better. The unexpected behavior and incidents, traditionally classified as "the discipline violation" and usually ending up with criticism by the teacher, can be tactfully used by the teacher to create a real context for the students to practise their English, and the effect is always better than the cold scene after the criticism.

3) The teachers should attach more importance to the teaching content and the students. 
Firstly, the teacher should know the teaching content very well. The analysis of the textbooks is the most important, including the different sections within a unit and all the units within a book with the aim of the flexible adjustment of the teaching content and objectives in the real class. Besides, the teacher should also appropriately adapt the textbook to the characteristics of the target students.

Secondly, the teachers should know the students better, not only the current knowledge structure and level of the students, but also the interests of the students, the physical and emotional states of the students at the class time, their learning style and habits, so that they can deal with unexpected resources more confidently and more efficiently in the real teaching.

\section{Suggestions on the Schools}

Firstly, from the interviews, we can see the school atmosphere influences the teachers to a large extent. A more democratic school is more likely to help the interactive decision making and the development of the students.

Secondly, the evaluation for the teachers can be diverse, not just the scores, but also the emotional aspects of the students.

Thirdly, the school can invite some experts in the field to give some training to the teachers and also organize the teachers to watch more live classes of the experienced teachers and have more communication among the teachers themselves.

Fourthly, the communication between the schools should also be promoted to help teachers to learn from each other.

Last but not the least, schools can also encourage their teachers to read more literature concerned with interactive decision making, especially the learning from the successful cases.

\section{LIMITATION}

The choice of the teachers in the two schools representative for two different level schools may just reflect some characteristics, therefore, the findings may not so applicable for other teachers and other schools; that's to say, the findings based on more teachers and more schools in the participants may be more valid in the future studies. Besides, every category of interactive decisions are worthy of closer examination.

\section{REFERENCES}

[1] Chen, Haiying. (2007). To create an energetic classroom from the dynamic generative resources. Hope Monthly, 7,84-86.

[2] Ding, Wenming. (2010). How to deal with the "unexpected resources" in class. Primary and Middle School Education Technology, 7, 87-89.

[3] Feng, Shuyi. (2006). A study on the teaching design and the dynamic generative resources in the primary English education. Foreign Language Teaching and Research, 6,42-45.

[4] Johnson, K. (1992b). The instructional decisions of pre-service English as a second language teacher: new directions for teacher preparation programs. In J.Flowerdew, M. Brock, and S.Hsia (eds.), Perspectives on Second Language Teacher Development. Hong Kong: City Polytechnic of Hong Kong, 15-34.

[5] Liu, Daoyi. (2008). A report on the development of Basic English Education. Shanghai: Shanghai Foreign Language Education Press.

[6] Richard, C.J. (1996). Reflective Teaching in Second Language Classrooms. Cambridge: The Press of University of Cambridge.

[7] Wang, Yan. (2011). To use the dynamic generative resources to build a vibrant English class. Foreign Language Education,1, 58-60.

[8] Wikipedia. (2009). Reggio Emilia Approach. http://en.wikipedia.org/wiki/Reggio_Emilia_approach\#Long-term_projects_as_vehicles_for_learning(accessed 26/10/2011).

[9] Ye, Lan. (1997). To make the classroom more vibrant. Education Research,3,6-10.

[10] Zhang, Qi. (2007). A study on the use of the dynamic generative resources in primary English Classroom. Foreign Language Teaching in Schools, 12, 17-19.

[11] Zhu, Zhiping. (2008). A study on the dynamic generative resources. Beijing: Higher Education Press.

Sha Zhu was born in Huai'an, Jiangsu Province of China in 1987. She received her master degree in Applied Linguistics from Capital Normal University, Beijing of China in 2012.

She is currently a teaching assistant in the School of Foreign Languages, Huaiyin Institute of Technology, Huai'an, Jiangsu Province of China. Her research interests include translation and English language teaching and learning, with a specific focus on Teacher's professional development. 